\title{
Design and rationale of the Danish trial of beta-blocker treatment after myocardial infarction without reduced ejection fraction: study protocol for a randomized controlled trial
}

Anna Meta Dyrvig Kristensen ${ }^{1 *}$ (D), Ann Bovin ${ }^{2}$, Ann Dorthe Zwisler ${ }^{3}$, Charlotte Cerquira ${ }^{4}$, Christian Torp-Pedersen ${ }^{5}$, Hans Erik Bøtker ${ }^{6}$, Ida Gustafsson ${ }^{1}$, Karsten Tange Veien ${ }^{7}, K^{2}$ ristian Korsgaard Thomsen ${ }^{8}$, Michael Hecht Olsen? Mogens Lytken Larsen ${ }^{10}$, Olav Wendelboe Nielsen ${ }^{1}$, Per Hildebrandt ${ }^{11}$, Sussie Foghmar ${ }^{12}$, Svend Eggert Jensen ${ }^{10}$, Theis Lange ${ }^{13}$, Thomas Sehested ${ }^{1}$, Tomas Jernberg ${ }^{14}$, Dan Atar ${ }^{15}$, Borja Ibanez ${ }^{16}$ and Eva Prescott ${ }^{1}$

\begin{abstract}
Background: Treatment with beta-blockers is currently recommended after myocardial infarction (MI). The evidence relies on trials conducted decades ago before implementation of revascularization and contemporary medical therapy or in trials enrolling patients with heart failure or reduced left ventricular ejection fraction (LVEF $\leq 40 \%)$. Accordingly, the impact of beta-blockers on mortality and morbidity following acute MI in patients without reduced LVEF or heart failure is unclear.

Methods/design: The Danish trial of beta-blocker treatment after myocardial infarction without reduced ejection fraction (DANBLOCK) is a prospective, randomized, controlled, open-label, non-blinded endpoint clinical trial designed to evaluate the efficacy of beta-blocker treatment in post-MI patients in the absence of reduced LVEF or heart failure. We will randomize 3570 patients will be randomized within 14 days of index Ml to beta-blocker or control for a minimum of 2 years. The primary endpoint is a composite of all-cause mortality, recurrent $\mathrm{Ml}$, acute decompensated heart failure, unstable angina pectoris, or stroke. The primary composite endpoint will be assessed through locally reported and adjudicated endpoints supplemented by linkage to the Danish national registers. A number of secondary endpoints will be investigated including patient reported outcomes and cardiovascular mortality. Data from similar ongoing trials in Norway and Sweden will be pooled to perform an individual patient data meta-analysis.

(Continued on next page)
\end{abstract}

\footnotetext{
* Correspondence: anna.meta.dyrvig.kristensen.02@regionh.dk;

akri0172@regionh.dk

'Department of Cardiology, Bispebjerg University Hospital, Copenhagen,

Denmark

Full list of author information is available at the end of the article
}

C C The Author(s). 2020 Open Access This article is licensed under a Creative Commons Attribution 4.0 International License, which permits use, sharing, adaptation, distribution and reproduction in any medium or format, as long as you give appropriate credit to the original author(s) and the source, provide a link to the Creative Commons licence, and indicate if changes were made. The images or other third party material in this article are included in the article's Creative Commons licence, unless indicated otherwise in a credit line to the material. If material is not included in the article's Creative Commons licence and your intended use is not permitted by statutory regulation or exceeds the permitted use, you will need to obtain permission directly from the copyright holder. To view a copy of this licence, visit http://creativecommons.org/licenses/by/4.0/ The Creative Commons Public Domain Dedication waiver (http://creativecommons.org/publicdomain/zero/1.0/) applies to the data made available in this article, unless otherwise stated in a credit line to the data. 
(Continued from previous page)

Discussion: DANBLOCK is a randomized clinical trial investigating the effect of long-term beta-blocker therapy after myocardial infarction in patients without heart failure and reduced LVEF. Results from the trial will add important scientific evidence to inform future clinical guidelines.

Trial registration: Clinicaltrials.gov, NCT03778554. Registered on 19 December 2018. European Clinical Trials Database, 2018-002699-42, registered on 28 September 2018.

Keywords: Myocardial infarction, Beta-blocker treatment, Long-term prognosis, Randomized controlled trial

\section{Background}

Beta-blockers have been an essential part of secondary prevention after myocardial infarction (MI) since landmark studies in the 1980s demonstrated a significantly lower mortality associated with beta-blocker treatment [1-3]. The benefits have been attributed to the negative chronotropic and ionotropic features, reducing oxygen demand, and improving coronary diastolic perfusion. Moreover, beta-blockers reduce the sympathetic activation and myocardial sensitivity to fatal arrhythmias [4, 5]. During the last decades reperfusion strategies and improved medical therapy for secondary prevention have substantially improved the prognosis for patients with MI [6]. Introduction of primary percutaneous coronary intervention (PCI) has resulted in increased salvage of myocardium, a smaller ischemic substrate, and a myocardium that is less susceptible to arrhythmias [7]. Hence, longterm oral beta-blocker therapy in patients without reduced left ventricular ejection fraction (LVEF) and heart failure (HF) after MI has been questioned $[8,9]$.

\section{Randomized controlled trials evaluating beta-blocker therapy}

The beta-blocker trials conducted in the 1980s and 1990 s were summarized in a meta-analysis of 82 randomized controlled trials documenting a significantly reduced mortality with beta-blocker therapy after MI [10]. However, the trials included in the meta-analysis were performed before revascularization was standard of care. In a recent meta-analysis comparing randomized controlled trials from the pre-reperfusion and reperfusion era, the mortality benefit was only seen in the prereperfusion era [11]. The incidence ratio for mortality in patients with and without beta-blocker treatment after $\mathrm{MI}$ in the 12 studies conducted in the reperfusion era was 0.98 (95\% confidence interval (CI) 0.92-1.05). In most trials, beta-blockers were given without systematically assessing LVEF, and although the incidence rates of MI and angina pectoris were reduced, there was an increased risk of $\mathrm{HF}$, cardiogenic shock, and drug discontinuation. Analyses were not stratified by LVEF and no trials in the reperfusion era had a follow-up period of more than 1 year. Consequently, it is not possible to extrapolate the results from the meta-analysis to contemporary long-term secondary prevention in patients without HF.

In the reperfusion era only one randomized controlled trial (CAPITAL-RCT) [12] has investigated the longterm efficacy of beta-blockers in patients with LVEF $\geq$ $40 \%$ after MI and successful PCI. The trial included patients with ST-elevation MI (STEMI) and suggested no benefit of carvedilol on a composite outcome (all-cause mortality, MI, hospitalization for HF and acute coronary syndrome) after a median follow up time of 3.9 years. However, the trial was not powered to detect a difference in the treatment effect for the primary endpoint as only 801 patients were randomized.

\section{Evidence from meta-analyses of observational studies}

Given the lack of contemporary randomized controlled trials from the reperfusion era addressing long-term beta-blocker therapy in MI patients without HF, a number of observational and registry studies have addressed the issue and have been summarized in meta-analyses [11, 13-16]. A meta-analysis of seven observational studies from 1996 to 2005 evaluated the benefit of long-term beta-blocker therapy ( $>6$ months) in STEMI patients with LVEF $>40 \%$ who underwent primary PCI [15]. The meta-analysis found long-term beta-blocker therapy to be associated with decreased all-cause mortality (combined hazard ratio $0.79,95 \%$ CI $0.65-0.97$ ). A total of 10,857 patients were included in the analysis and followup duration ranged from 6 months to 5.2 years. Another meta-analysis included ten observational studies of patients treated with PCI for either non-ST-elevation MI (NSTEMI) or STEMI with a follow up of at least 3 months. No significant mortality benefit was found in the subgroup of patients with preserved LVEF (relative risk 0.79 , 95\% CI 0.59-1.07) [16]. Follow-up duration ranged between 6 months and 4 years and a potential efficacy of beta-blocker therapy appeared to gradually disappear > 1 year after MI. A third meta-analysis including a systematic review based on 16 observational studies from 2010 to 2017 found a reduction in all-cause mortality among almost 200,000 post-MI patients without HF (rate ratio 0.74, 95\% CI 0.64-0.85). However, publication bias and a small study effect were present. The beneficial effect of beta-blocker therapy disappeared 
when controlling for bias, suggesting no improved survival with beta-blocker therapy (rate ratio 0.90, 95\% CI 0.77-1.04) [13].

Observational studies have thus yielded disparate results and one concern is that they are likely to suffer from confounding by indication as beta-blockers are often avoided in, for example, elderly patients, who have a high burden of comorbidity. In a UK registry-based study including 179,810 MI patients with LVEF > 30\%, beta-blockers were prescribed in 95\% of the patients. Significant differences in baseline characteristics among the beta-blocker and non-beta-blocker group were evident [17], suggesting that use of beta-blocker therapy is so wide-spread that observational studies are not likely to clarify the value of beta-blocker therapy, even when applying advanced models to adjust for bias. Indeed, this registry-based study found lower mortality rate among patients treated with beta-blockers, but after propensity score and instrumental variable analysis, no difference in survival was found among the two groups.

\section{Guideline recommendations}

Given these uncertainties, contemporary guidelines differ regarding recommendations of beta-blocker therapy. The American College of Cardiology/American Heart Association (ACC/AHA) recommend beta-blocker therapy with a class I recommendation (level of evidence (LOE) B) in patients with STEMI [8], but acknowledge that long-term beta-blocker therapy has not been prospectively addressed. The European Society of Cardiology (ESC) Guidelines for the management of acute MI in patients presenting with STEMI recommend that oral beta-blocker therapy should be considered during hospital stay and continued thereafter in all patients without contraindications with a class IIa recommendation (LOE B) [18]. For NSTEMI patients with preserved LVEF the ACC/AHA guidelines find it reasonable to continue beta-blocker therapy with a class IIa recommendation (LOE C) [19], whereas the ECS 2015 guideline has no recommendations concerning non-ST-elevation acute coronary syndromes [20]. In contrast, the 2013 NICE guideline recommends continuing beta-blocker therapy for at least 1 year after MI in patients without reduced LVEF or HF [21].

\section{Compliance and side effects}

Beta-blockers are generally well tolerated, but sideeffects are common and may adversely affect quality of life $[1,2]$. Compared with other cardiovascular medications, a lower compliance with beta-blocker treatment is found, suggesting a relation to side effects [22, 23]. However, not all of these side effects are supported by evidence from randomized trials [24].

\section{Objectives}

Given the lack of clear evidence, there has been a call for randomized trials $[8,9,25,26]$. The objective of the Danish trial of beta-blocker treatment after myocardial infarction without reduced ejection fraction (DANBLOCK) is to evaluate the continued efficacy of longterm beta-blocker therapy after MI in patients without HF. The study hypothesizes that beta-blocker therapy is superior to standard of care without beta-blockers following MI in patients without reduced LVEF (>40\%) and $\mathrm{HF}$ receiving contemporary treatment.

\section{Methods/design}

\section{Trial design}

DANBLOCK is a Danish multicenter, prospective, randomized, controlled, open-label, non-blinded endpoint clinical trial designed to evaluate the benefits of longterm oral beta-blocker therapy in patients discharged after an acute MI without HF. The aim is to randomize 3570 patients 1:1 to beta-blocker therapy or no betablocker therapy. A study overview is presented in Fig. 1. The expected enrolment period is 2 years and the anticipated duration of the trial is approximately 4 years with subsequent publication of trial results. The trial is designed to achieve a pre-specified number of events. Study patients will be followed for all clinical endpoints until the end of the trial.

\section{Eligibility criteria}

Study patients must be at least 18 years old, have suffered a first-time or recurrent MI within the previous 14 days, and have an LVEF $>40 \%$ estimated by an echocardiographic examination after MI. MI is defined using the criteria developed by the Third Universal Definition of Myocardial Infarction [27]. Indications and contraindications to beta-blocker therapy are all relative and assessed by the attending physician and study nurse. Any indication or contraindication will exclude the patient from the trial. Patients treated with a beta-blocker prior to the MI or initiated during the current hospital admission are also eligible (e.g., if the indication is based on a prior $\mathrm{MI}$ ). Eligible patients may be randomized prior to, after, or without a coronary angiography. Patients will be randomized after informed consent has been obtained by the study personal. A full list of inclusion and exclusion criteria is given in Table 1.

\section{Medical treatment and adherence}

After informed consent has been collected, study patients will be randomized 1:1 to receive either betablocker therapy or standard treatment without betablockers. After randomization both treatment groups will receive standard care after MI and no trial-specific visits are planned. Type and dosage of beta-blocker are 


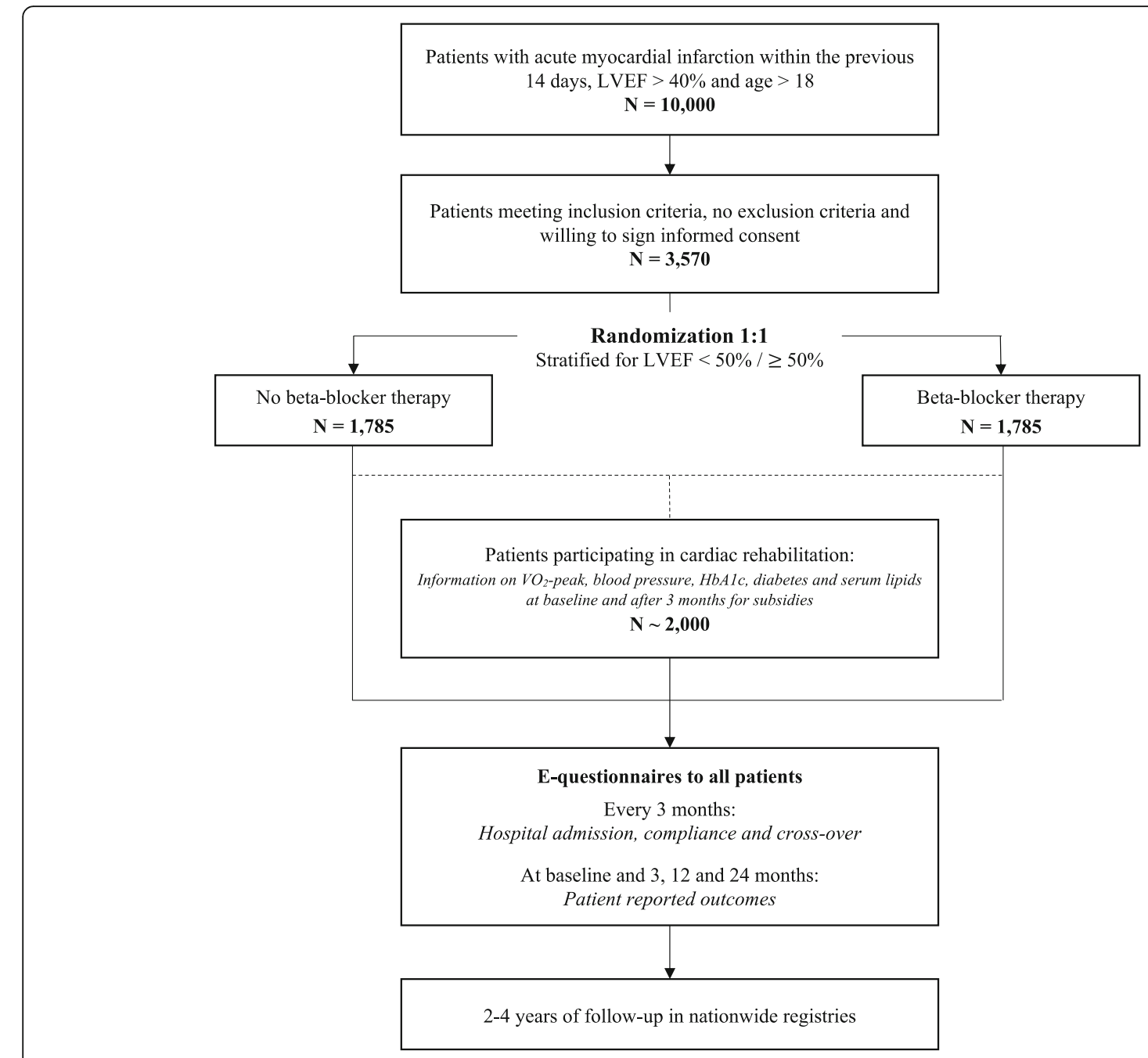

Fig. 1 Study overview

at the discretion of the treating physician. The following generic beta-blockers and dosages are recommended: metoprolol succinate up to a total dosage of $200 \mathrm{mg}$ daily, bisoprolol up to a total dosage of $10 \mathrm{mg}$ daily, carvedilol up to a total dosage of $50 \mathrm{mg}$ daily, and nebivolol up to a total dosage of $10 \mathrm{mg}$ daily. It is recommended to titrate to the highest dosage tolerated. The patient will cover cost of medicine.

The patient's general practitioner will be informed of the trial in the discharge letter and will be encouraged to maintain the patient in the group to which he or she was randomized. Randomized patients will receive a pocket card containing a brief explanation of the trial, information on the randomization group, and contact information on the local responsible investigator. Information on compliance, dosage, and cross-over will be monitored through e-questionnaires to the patients every 3 months. In addition, concomitant medication at the time of randomization and throughout the study period will be ascertained through linkage to the Danish Prescription Registry at study end.

\section{Data collection and study endpoints \\ Primary endpoints and their rationale}

The primary endpoint is a composite of all-cause mortality, recurrent MI, acute decompensated HF, unstable angina pectoris, or stroke. The primary composite endpoint was chosen for several reasons: a composite endpoint addresses a multiplicity of concerns and an integrated effect of beta-blocker therapy is most relevant when considered for later recommendations. All components in the composite endpoint are affected by the use of beta-blockers based on evidence from previous trials. The landmark trials found a mortality benefit from betablocker treatment $[1-3]$ and a relative reduction of reinfarction $[2,3]$ and no association was seen between beta-blocker treatment and risk of incident HF [28]. In contrast, an increased risk of $\mathrm{HF}$ with beta-blocker treatment is 
Table 1 Inclusion and exclusion criteria

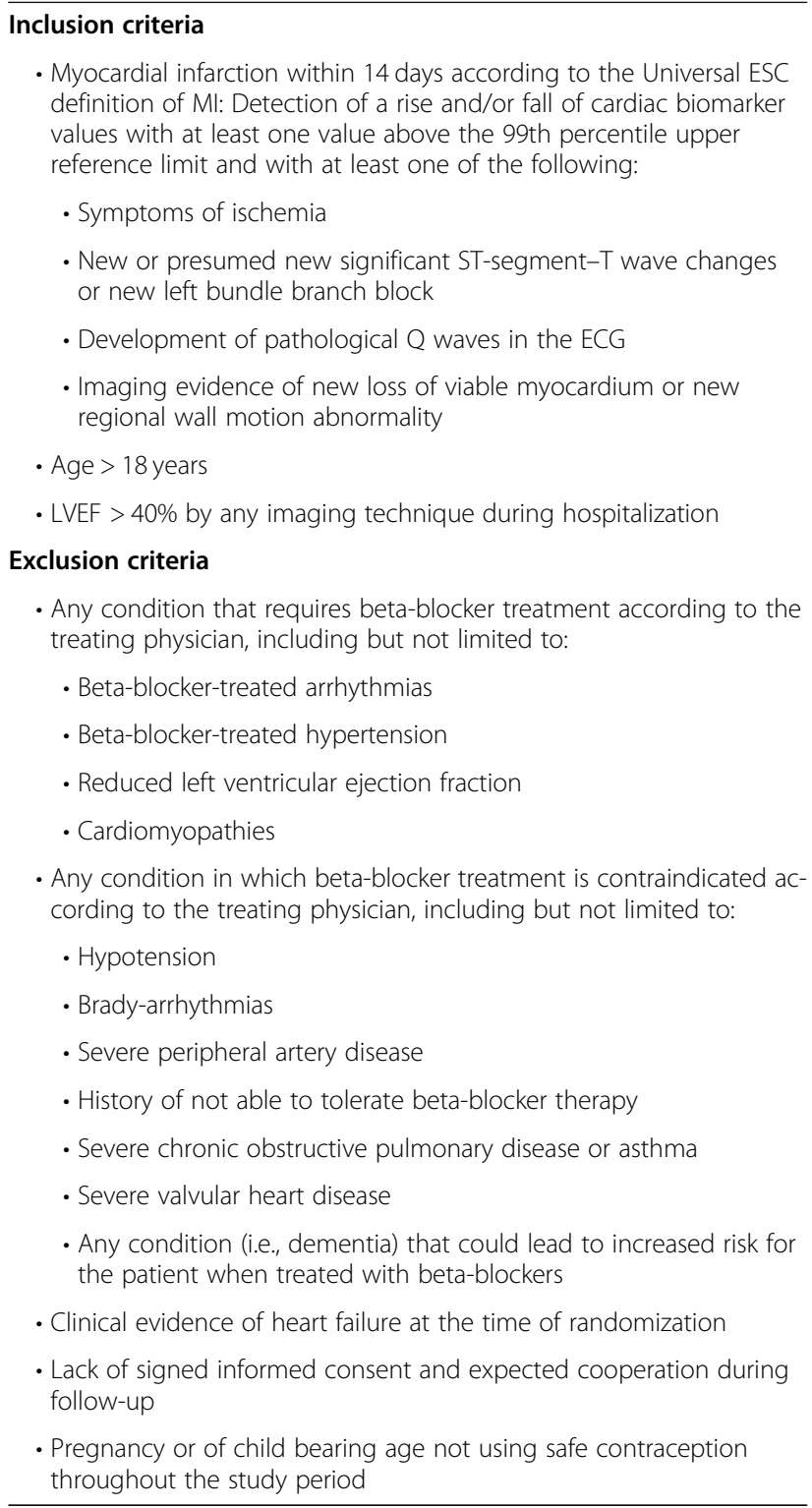

supported by a meta-analysis of 12 randomized controlled trials from the reperfusion era [11]. Stroke has been included as a component of the composite endpoint as poorer blood pressure control can potentially occur in the non-beta-blocker group, increasing the risk of stroke. Further, use of a single primary outcome would have resulted in an unfeasible sample size. The primary composite endpoint will be assessed through locally reported and adjudicated endpoints. Adjudication will be performed through review of hospital records, applying endpoint definitions following the objective criteria in the 2017 Cardiovascular and Stroke Endpoint Definition for Clinical Trials [29]. At study end data will be supplemented by linkage to the Danish administrative and clinical registers. The use of registers will ensure no outcome data are missed.

\section{Secondary endpoints and their rationale}

The secondary endpoints are listed in Table 2 and a schedule of enrolment, interventions, and assessments is presented in Table 3. Among these is the effect of longterm beta-blocker therapy on quality of life as studies investigating the side effects of beta-blocker treatment have given disparate results. Previous trials have demonstrated that beta-blocker therapy may increase fatigue, institute sexual dysfunction, and lead to sleep disorders, gastrointestinal discomfort, cold hands, and feet, bronchospasm, and depressive symptoms [2]. In a recent systemic review of 15 placebo-controlled studies, however, no significant increase in depressive symptoms was found with betablocker treatment and only a small increased risk of fatigue and sexual dysfunction were seen [30].

Despite complete revascularization, a significant proportion of patients continues to have angina, which affects quality of life and is associated with anxiety and depression [31, 32]. Beta-blockers are first-line treatment of angina pectoris [33], but whether routine treatment will improve symptoms and quality of life in a contemporary post-MI population is unknown.

Patient reported outcomes will be collected at baseline prior to randomization and after 3,12 , and 24 months through questionnaires (electronic or paper). The

Table 2 Primary and secondary endpoints

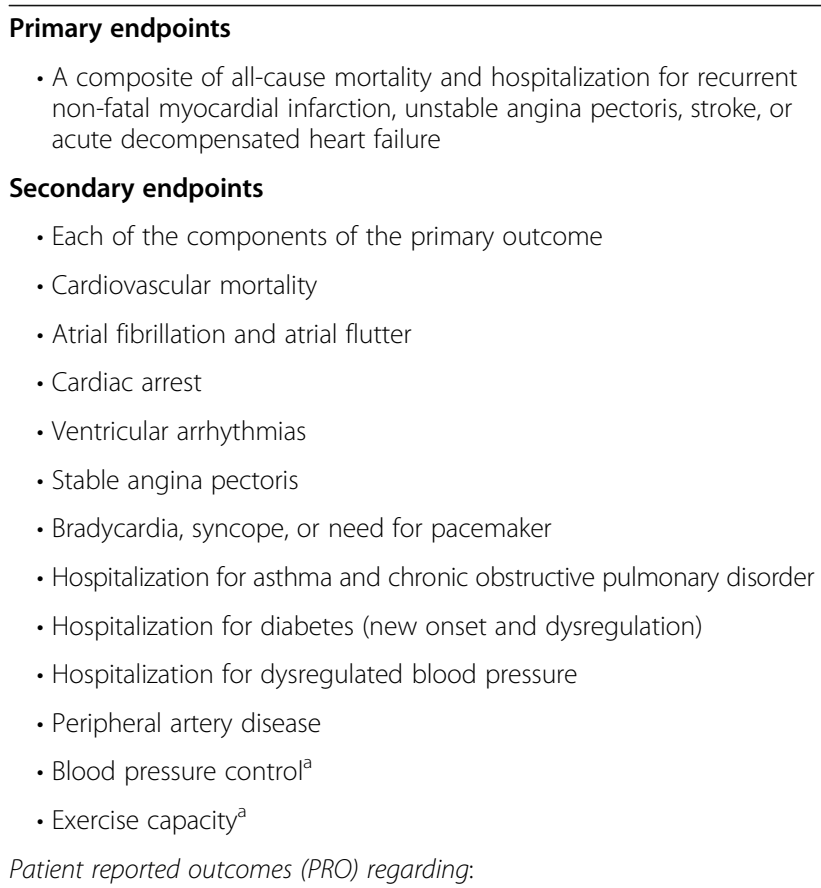

- Health-related quality of life, depression, sexual dysfunction, angina burden following MI, and sleep disorders

${ }^{\mathrm{a}}$ Available for patients attending cardiac rehabilitation 
Table 3 Schedule of enrolment, interventions, and assessments

\begin{tabular}{|c|c|c|c|c|c|c|}
\hline \multirow[t]{2}{*}{ Time and assessment } & \multirow{2}{*}{$\begin{array}{l}\text { Enrolment } \\
\text { At randomization }\end{array}$} & \multicolumn{4}{|c|}{ Treatment period following randomization } & \multirow[t]{2}{*}{ Study end } \\
\hline & & Every 3 months & 3 months & 1 year & 2 year & \\
\hline $\begin{array}{l}\text { Eligibility screen, informed consent, allocation to treatment group, } \\
\text { and collection of baseline data }{ }^{a}\end{array}$ & $x$ & & & & & \\
\hline Self-reported questionnaires on quality of life and symptom burden ${ }^{\mathrm{b}}$ & $x$ & & $x$ & $x$ & $x$ & \\
\hline Risk factor control and benefit from cardiac rehabilitation ${ }^{c}$ & & & & & & $x$ \\
\hline Adherence to treatment group ${ }^{d}$ & & $x$ & & & & $x$ \\
\hline Information on hospital admissions ${ }^{\mathrm{e}}$ & & $x$ & & & & $x$ \\
\hline Endpoints from registry data & & & & & & $x$ \\
\hline \multicolumn{7}{|c|}{$\begin{array}{l}\text { a Data collected during hospital admission or at subsequent visit } \\
\text { b The following e-questionnaires on patient-reported outcomes will be administered: EQ5D, HADS, IIEF/FSFI (short versions), Bergen Insomnia Scale, NYHA, CCS, } \\
\text { and SAQ (for those reporting symptoms of angina) } \\
\text { c Data on blood pressure, serum lipids, diabetes, HbA1c, and VO2peak before and after rehabilitation through registry linkage to the Danish Heart Rehabilitation } \\
\text { Database. The data are available for patients participating in cardiac rehabilitation } \\
\text { d Self-reported continued adherence to treatment group will be gathered every } 3 \text { months. By linkage to the National Prescription Register at study end, adherence } \\
\text { to treatment group as well as other medications will be assessed } \\
\text { e Every } 3 \text { months the patient's vital status and hospitalizations will be investigated through self-reported questionnaires or review of electronic health records. All } \\
\text { hospital admissions will be evaluated for a possible relationship with treatment group. At study end hospital admission or death from a primary or secondary } \\
\text { endpoint will be ascertained from the Danish National Patient Register }\end{array}$} \\
\hline
\end{tabular}

following patient reported outcomes will be assessed: quality of life (EuroQol-5 Domain (EQ5D) [34]), anxiety and depression (Hospital Anxiety and Depression Scale (HADS) [35]), sexual dysfunction (short versions of International Index of Erectile Function (IIEF) [36] and Female Sexual Function Index (FSFI) [37]), sleep disorders (Bergen insomnia scale [38]), and symptom-burden after MI (New York Heart Association classification (NYHA), Canadian Cardiovascular Society grading of angina pectoris (CCS), Seattle Angina Questionnaire (SAQ) [39]).

Beta-blocker therapy is no longer first line treatment for hypertension; however, routine use after MI may give better blood pressure control than individual uptitration and may be a part of a beneficial effect of beta-blockers. Hence, blood pressure control has been chosen as a secondary endpoint. The use of beta-blockers in patients with diabetes may reduce insulin sensitivity [40], increase plasma glucose, mask hypoglycaemic symptoms, or increase the risk of new onset diabetes [41-43], but limited data are available. Furthermore, beta-blockers are suspected to limit $\mathrm{VO}_{2}$-peak, an objective indicator of physical capacity and a predictor of prognosis. DANBLOCK will ascertain data from the Danish Cardiac Rehabilitation Database (DHRD), a nationwide rehabilitation database of adults treated for ischemic cardiac disease in a Danish hospital. The database contains several quality indicators, including, but not limited to, LVEF, $\mathrm{VO}_{2}$-peak, incidence and control of diabetes, blood pressure control, cholesterol levels, and adherence to and dosage of beta-blockers, statins, and platelet inhibitors.

\section{Study organization, safety, and monitoring}

DANBLOCK is a nationwide Danish trial endorsed by the Danish Society of Cardiology. The trial is investigator- initiated and currently 26 of the 29 departments of cardiology in Denmark are participating. A steering committee is responsible for conducting the trial and reporting of the trial results.

Every 3 months patient health records will be reviewed for clinical endpoints and hospitalization with possible causal relation to the treatment or non-treatment with beta-blockers.

Three months after the first patient is randomized and every 6 months thereafter a Data Safety Monitoring Board (DSMB) consisting of two senior cardiologists and one experienced trial statistician will overview safety. In case of an imbalance in event rates between the treatment arms or if the DSMB is of the conviction that the risk to current and future trial patients outweighs the potential impact of continuing the trial, the DSMB will recommend the steering committee to discontinue the trial. DSMB members are independent and not otherwise involved in the trial.

The trial may be discontinued for futility if the inclusion rate is lower than expected and the trial cannot reach the needed number of patients within a reasonable time frame and in case of excessive cross-over. The steering committee will make any decisions of discontinuation.

\section{Patient and public involvement}

Patient groups are involved as research partners to ensure that the trial focuses on issues relevant to the patients and the public. Prior to enrolment of the first patient a patient expert group has been established with members from different backgrounds reflecting patients eligible for the trial. The group has met to share their experiences with beta-blocker treatment and to review and develop patient material, questionnaires, and e-mails to the patients included in the trial. Further meetings of 
the group will be undertaken during the study period to achieve adequate participant enrolment and ensure continued patient involvement in the process of interpretation and dissemination of results.

\section{Ongoing beta-blocker trials}

In Norway and Sweden trials with comparable inclusion criteria and endpoints are ongoing: The Swedish Randomized Evaluation of Decreased Usage of betablockers after myocardial infarction in the SWEDEHEART registry (REDUCE-SWEDEHEART, NCT03278509) and the Norwegian BEtablocker Treatment After acute Myocardial Infarction in revascularized patients without reduced left ventricular ejection fraction (BETAMI, NCT03646357 [44]). Both trials are designed as superiority trials and aim to include 7000 and 10,000 patients, respectively. Table 4 shows the characteristics of the three Scandinavian studies. The trials primarily differ in terms of the primary endpoint and the LVEF cutoff value.

Furthermore, a Spanish-Italian trial, REBOOT, is ongoing. REBOOT is randomizing patients after MI with a LVEF $>40 \%$ to either beta-blocker therapy or standard treatment without beta-blockers (NCT 03596385). The primary outcome of REBOOT is the 3-year incidence of a composite of all-cause mortality, reinfarction, and HF admission.

\section{Statistical considerations}

The trial is designed to reach a pre-specified number of events and patients will be followed for all clinical endpoints until the end of the trial. Loss to follow-up is considered negligible due to almost complete coverage by the national registers. We must accumulate 900 events to be able to detect an effect with a power of $80 \%$ and a hazard ratio of 1.2 for the non-treated group compared with the treated with regard to the primary endpoint. Based on data from the Danish nationwide registry from 2010 to 2015, 9100 patients in Denmark suffer a firsttime or recurrent MI annually and the monthly risk of the primary composite endpoint is $1.62 \%$. Some patients will not be eligible to participate in the trial or will not wish to participate; hence, it is estimated that 1785 patients annually will be eligible and willing to sign informed consent. It is expected that a 2-year recruitment period and subsequent follow-up of 3570 patients with aggregated events will yield the desired 900 events. In case of a lower event rate, the inclusion period and the follow-up period will be prolonged and a greater number of patients will be included. Patients will be randomized $1: 1$ and stratified by LVEF $41-49 \%$ and $\geq 50 \%$ via a central computerized system. Analysis will be performed using the intention-to-treat principle with a significance level of $5 \%$. In addition, a per-protocol analysis will be

Table 4 Characteristics of DANBLOCK, REDUCE-SWEDEHEART, and BETAMI

\begin{tabular}{|c|c|c|c|}
\hline & DANBLOCK & REDUCE-SWEDEHEART & BETAMI \\
\hline \multicolumn{4}{|l|}{ Inclusion criteria } \\
\hline Age & $\geq 18$ years & $\geq 18$ years & $\geq 18$ years \\
\hline Ml definition & The universal definition of MI & $\begin{array}{l}\text { The universal definition of Ml } \\
\text { (type 1) }\end{array}$ & $\begin{array}{l}\text { The universal definition of Ml } \\
\text { (type 1) }\end{array}$ \\
\hline Randomized prior to & Day 14 after Ml & Day 7 after Ml & Not specified \\
\hline Revascularization & No criteria for revascularization & $\begin{array}{l}\text { Obstructive coronary artery } \\
\text { disease documented by } \\
\text { coronary angiography }\end{array}$ & $\begin{array}{l}\mathrm{PCl} \text { or thrombolysis during } \\
\text { hospitalization }\end{array}$ \\
\hline LVEF cutoff value & $>40 \%$ & $\geq 50 \%$ & $\geq 40 \%$ \\
\hline Exclusion criteria & $\begin{array}{l}\text { Any medical condition where } \\
\text { beta-blocker therapy is indicated } \\
\text { or contraindicated according } \\
\text { to the treating physician }\end{array}$ & $\begin{array}{l}\text { Any medical condition where } \\
\text { beta-blocker therapy is indicated } \\
\text { or contraindicated according to } \\
\text { the treating physician }\end{array}$ & $\begin{array}{l}\text { Any medical condition where } \\
\text { beta-blocker therapy is indicated } \\
\text { or contraindicated according to } \\
\text { the treating physician }\end{array}$ \\
\hline Primary endpoints & $\begin{array}{l}\text { A composite of all-cause mortality } \\
\text { and hospitalization for recurrent } \\
\text { non-fatal MI, unstable angina } \\
\text { pectoris, stroke, and acute } \\
\text { decompensated heart failure }\end{array}$ & $\begin{array}{l}\text { Time to the composite of } \\
\text { death of any cause or Ml }\end{array}$ & $\begin{array}{l}\text { Time to the composite of all } \\
\text { cause mortality or non-fatal Ml }\end{array}$ \\
\hline $\begin{array}{l}\text { Expected number of randomized } \\
\text { patients }\end{array}$ & 3570 & 7000 & 10,000 \\
\hline Expected number of events & 900 & 944 & 794 \\
\hline $\begin{array}{l}\text { Expected number of events } \\
\text { to contribute to a pooled } \\
\text { meta-analysis }\end{array}$ & 632 & 944 & 794 \\
\hline $\begin{array}{l}\text { Individual study power if } \\
\text { true HR was } 1.2\end{array}$ & 0.619 & 0.797 & 0.732 \\
\hline
\end{tabular}


carried out. Withdrawal of consent is not expected to be an issue throughout the study period.

\section{Combined analysis of the Scandinavian beta-blocker trials}

An adequately powered trial is needed to resolve the question of long-term beta-blocker therapy after MI and allow for subgroup analysis, which is possible with a meta-analysis based on data from the three Scandinavian studies. Hence, BETAMI, REDUCE-SWEDEHEART, and DANBLOCK will collaborate on a combined individual patient data meta-analysis when follow-up has ended and data are available. By joining the three studies more than 20,000 patients will be eligible for subgroup analysis, including midrange LVEF, sex, age, treatment dosage, and type of MI. Collating three nationwide trials with pragmatic inclusion criteria, a diverse patient population will increase generalizability of the results. To be able to conduct the meta-analysis, DANBLOCK will report the effect measure as time to the composite of death from any cause or MI, similarly to REDUCESWEDEHEART and BETAMI. Differences in inclusion and exclusion criteria are present (Table 4) but arguably less than typically seen in comparable meta-analyses. With a combined expected number of events of 2370 and using a standard random effects meta-analysis, the meta-analysis will have an overall power of 0.993 to detect a HR of 1.2 using a two-sided test at 5\% significance level. Figure 2 compares the power for different sample sizes, expressed as expected number of events, and assumed effect size if data originate from a multicenter trial and the planned random effects meta-analysis. When varying the total sample size, the ratios between the studies' sample sizes are kept fixed as in the actual
Scandinavian sample sizes. As a benchmark, Fig. 2 also reports the power obtained if the same number of patients had been included in a single large trial.

\section{Trial status}

The first patient was enrolled December 18th 2018. Recruitment is expected to be complete in the 2021 and end of follow-up in 2022. Results will be available in 2023. The full protocol is available to the public online. The final version is 1.7 November 26th 2018. In case of important protocol modifications, changes will be communicated by e-mail and/or letter to relevant parties (investigators, participants, etc.).

\section{Discussion}

DANBLOCK will add important scientific evidence for the efficacy of beta-blocker treatment following MI in patients without HF. The trial is designed as a prospective, randomized, controlled, open-label, non-blinded endpoint clinical trial. The design is pragmatic and similar to standard clinical practice, which increases the generalizability of its conclusions to routine medical care [45]. It is possible to randomize patients who have not undergone coronary angiography and patients who were treated with a beta-blocker prior to the MI. This will allow for a greater number of patients being randomized, reducing the total inclusion time. A limitation of the selected design is the lack of a placebo group with particular relevance to affect patient-reported outcomes. To minimize this effect patients will complete the baseline questionnaire before randomization.

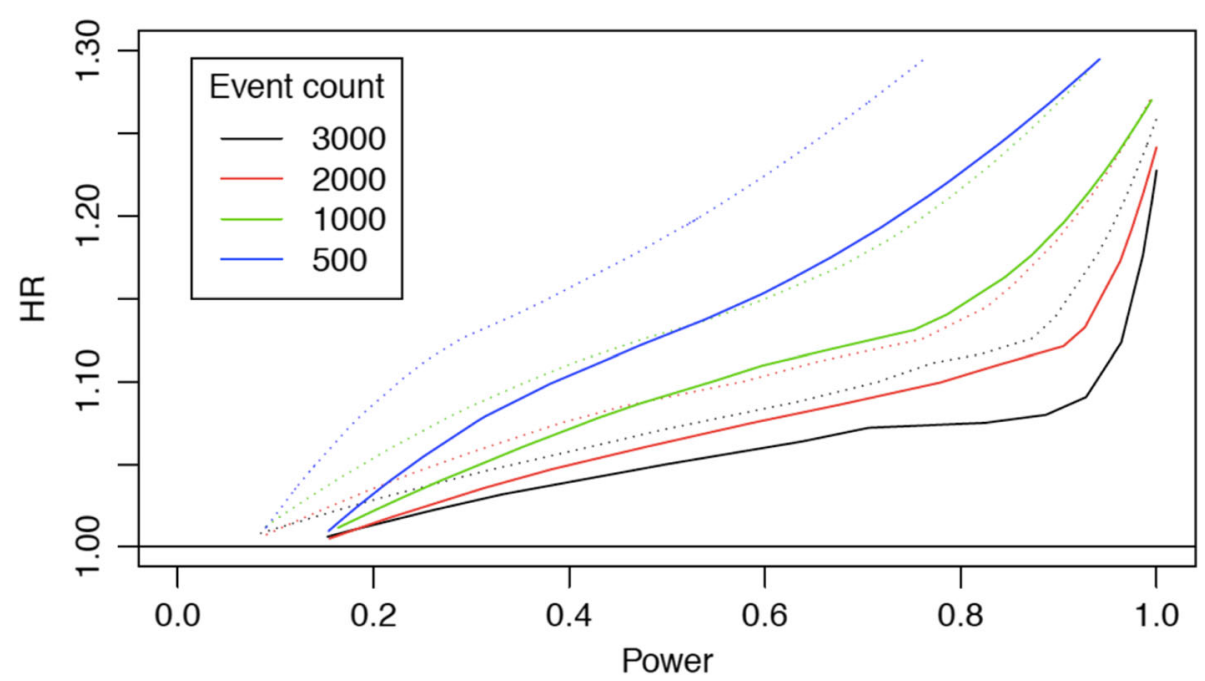

Fig. 2 Minimal detectable difference between groups (HR) and statistical power in the planned meta-analyses of the three Scandinavian trials. For comparison the greater statistical power in a single multicenter trial with the same number of events is also depicted. The solid line indicates analysis based on data from a single multicenter trial; the dashed line indicates meta-analysis performed with a random-effects model 


\section{LVEF cutoff value}

Beta-blocker therapy has a mortality benefit in patients with HF [46]. Consequently, patients with clinical evidence of $\mathrm{HF}$ or $\mathrm{LVEF} \leq 40 \%$ are excluded from the trial. The 2016 ESC guideline introduced the classification of LVEF into preserved ( $\geq 50 \%)$, midrange (40-49\%), and reduced LVEF (<40\%) [47]. Accordingly, few data exist on midrange LVEF. Whether or not to include patients with midrange LVEF was considered in depth. A metaanalysis of beta-blockers for HF with reduced, midrange, and preserved ejection fraction demonstrated no evidence of benefit of beta-blockers for all-cause mortality when LVEF was $>40 \%$ in sinus rhythm [48]. The ongoing trials DANBLOCK, BETAMI, and REBOOT and the published CAPITAL-RCT [12] all include patients with midrange LVEF. Hopefully, these trials will resolve whether beta-blockers are beneficial in this group of patients.

\section{Dosage and duration of beta-blocker therapy}

The appropriate length of beta-blocker therapy after MI remains unclear because this issue has not been addressed in any randomized controlled trial. In a systematic review of propensity score matched observational studies and regression cohort studies of long term beta-blocker treatment (> 1 year, median: 3 years) in post-MI patients without HF, the majority of studies failed to identify a benefit on mortality or major cardiovascular events with long-term beta-blocker therapy [49]. DANBLOCK, BETAMI, REBOOT, and REDUCE-SWEDEHEART will investigate the long-term efficacy with an expected treatment duration of 2-4 years.

The dosages used in contemporary clinical practice are lower than dosages used in previous randomized clinical trials [50] and may contribute to the lack of a mortality benefit seen in some observational studies. Interestingly, register-based studies suggest that an increased survival might not be present in patients treated with dosages approximating those from the early beta-blocker trials compared with a lower dosage [51]. A register-based study showed similar rates of major adverse cardiac events among patients receiving low-dose and high-dose betablocker therapy (respectively $\leq 25 \%$ and $\geq 50 \%$ of an equivalent daily dose of $200 \mathrm{mg}$ metoprolol) during 6-24 months after acute coronary syndrome (hazard ratio 1.03, 95\% CI 0.70-1.50) [52]. In DANBLOCK the type and dosage of beta-blocker are at the treating cardiologist's choice. It is recommended to achieve the highest dosage tolerated. In the discharge letter it is recommended to increase the dosage at cardiac rehabilitation and subsequent follow-up.

\section{Utility of withdrawal studies}

Since the 1980s the proportion of adults over 65 years who are prescribed five or more medications has tripled [53]. The effectiveness of secondary prevention depends on patient adherence and patients may only adhere to half of the treatment prescribed [54]. In studies investigating adherence to secondary preventive therapies after MI, only half of the population were adherent to ACE inhibitors/ARBs, beta-blockers, and statins [23]. In the same study, mortality was equal between a group adherent to all three medications and a group only adherent to ACE inhibitors/ARBs and statins. Baseline characteristic were equal in the two groups. These findings demonstrate the need for withdrawal studies to ensure that the patients are adherent to the most efficacious treatment. It is in line with the ESC's suggestion to improve research on secondary prevention after acute coronary syndromes to replace old evidence-based treatments instead of incrementally adding new ones [55].

\section{Conclusion}

DANBLOCK will add important scientific evidence for the efficacy of beta-blocker treatment following $\mathrm{MI}$ in patients without HF and reduced LVEF. The collaborative effort of the three Scandinavian studies will have the potential of changing guidelines and clinical practice to the benefit of these MI patients.

\section{Supplementary information}

Supplementary information accompanies this paper at https://doi.org/10. 1186/s13063-020-4214-6.

Additional file 1. World Health Organization trial registration data set.

Additional file 2. Overview of meta-analyses regarding beta-blocker therapy after myocardial infarction.

\section{Abbreviations}

ACC/AHA: American College of Cardiology/American Heart Association; BETAMI: BEtablocker Treatment After acute Myocardial Infarction in revascularized patients without reduced left ventricular ejection fraction; $\mathrm{Cl}$ : Confidence interval; DANBLOCK: Danish trial of beta-blocker treatment after myocardial infarction without reduced ejection fraction; DHRD: Danish Cardiac Rehabilitation Database; DSMB: Data Safety Monitoring Board; ESC: European Society of Cardiology; HF: Heart failure; LOE: Level of evidence; LVEF: Left ventricular ejection fraction; MI: Myocardial infarction; NSTEMI: Non-ST-elevation myocardial infarction; PCl: Primary percutaneous coronary intervention; REDUCE-SWEDEHEART: Swedish Randomized Evaluation of Decreased Usage of betablockers after myocardial infarction in the SWEDEHEART registry; STEMI: ST-elevation myocardial infarction

\section{Acknowledgements}

Not applicable.

\section{Authors' contributions}

AMK drafted the initial manuscript. TL performed the analysis and prepared Fig. 2. All authors contributed to the design of the trial and have read and approved the final manuscript.

\section{Funding}

The trial has received grants from the Novo Nordisk Foundation and the Danish Heart Foundation. The Novo Nordisk Foundation and the Danish Heart Foundation are not otherwise involved in the trial.

\section{Availability of data and materials}

Data sharing is not applicable to this article. No datasets have been generated yet as the study is still ongoing. 


\section{Ethics approval and consent to participate}

The Danish Medicines Agency, the Danish Data Protection Agency, and the Danish Committee on Health Research Ethics have approved the trial. The trial is performed in accordance with ICH GCP guidelines and the Helsinki declaration. Informed consent will be collected prior to randomization.

\section{Consent for publication}

Not applicable.

\section{Competing interests}

The authors declare that they have no competing interests.

\section{Author details}

'Department of Cardiology, Bispebjerg University Hospital, Copenhagen, Denmark. ${ }^{2}$ Department of Cardiology, Sygehus Lillebæalt, Vejle, Denmark. ${ }^{3}$ Danish Centre for Rehabilitation and Palliative Care, Odense University Hospital and University of Southern Denmark, Odense, Denmark. ${ }^{4}$ The Regional Clinical Quality Development Program, Aarhus, Denmark. ${ }^{5}$ Department of Epidemiology and Biostatistics, Aalborg University Hospital, Aalborg, Denmark. ${ }^{6}$ Department of Cardiology, Aarhus University Hospital, Aarhus, Denmark. ${ }^{7}$ Department of Cardiology, Odense University Hospital, Odense, Denmark. ${ }^{8}$ Department of Cardiology, Sydvestjysk Sygehus, Esbjerg, Denmark. ${ }^{9}$ Department of Internal Medicine, Holbæk Hospital, Holbæk, Denmark. ${ }^{10}$ Department of Cardiology, Aalborg University Hospital, Aalborg, Denmark. " Department of Cardiology, Frederiksberg Heart Clinic, Copenhagen, Denmark. ${ }^{12}$ Department of Cardiology, Hvidovre-Amager Hospital, Hvidovre, Denmark. ${ }^{13}$ Section of Biostatistics, University of Copenhagen, Copenhagen, Denmark. ${ }^{14}$ Department of Clinical Sciences, Division of Cardiology, Karolinska Institutet, Danderyd Hospital, Stockholm, Sweden. ${ }^{15}$ Department of Cardiology, Oslo University Hospital, Oslo, Norway. ${ }^{16}$ Centro Nacional de Investigaciones Cardiovasculares (CNIC) \& IISFundación Jiménez Díaz \& CIBERCV, Madrid, Spain.

\section{Received: 4 February 2020 Accepted: 27 February 2020} Published online: 23 May 2020

\section{References}

1. Group NMS. Timolol-induced reduction in mortality and reinfarction in patients surviving acute myocardial infarction. N Engl J Med. 1981;304:801-7.

2. The National Heart $L$, and Blood Institute, Bethesda, MD. A randomized trial of propranolol in patients with acute myocardial infarction. I. Mortality results. JAMA. 1982;247:1707-14.

3. Hjalmarson A, Herlitz J, Holmberg S, Ryden L, Swedberg K, Vedin A, et al. The Goteborg metoprolol trial. Effects on mortality and morbidity in acute myocardial infarction. Circulation. 1983;67:126-32.

4. McCance AJ, Thompson PA, Forfar JC. Increased cardiac sympathetic nervous activity in patients with unstable coronary heart disease. Eur Heart J. 1993;14:751-7.

5. Paladino $L$, Sinert R, Brandler E. A review and meta-analysis of studies on the effect and timing of beta-blocker administration in patients with STsegment elevation myocardial infarction. Hosp Pract (1995). 2010;38:63-8.

6. Rogers WJ, Frederick PD, Stoehr E, Canto JG, Ornato JP, Gibson CM, et al. Trends in presenting characteristics and hospital mortality among patients with ST elevation and non-ST elevation myocardial infarction in the National Registry of Myocardial Infarction from 1990 to 2006. Am Heart J. 2008;156:1026-34.

7. Ibanez B, Heusch G, Ovize M, Van de Werf F. Evolving therapies for myocardial ischemia/reperfusion injury. J Am Coll Cardiol. 2015;65:1454-71.

8. O'Gara PT, Kushner FG, Ascheim DD, Casey DE Jr, Chung MK, de Lemos JA, et al. 2013 ACCF/AHA guideline for the management of ST-elevation myocardial infarction: a report of the American College of Cardiology Foundation/American Heart Association Task Force on Practice Guidelines. J Am Coll Cardiol. 2013;61:e78-e140.

9. Mickley $\mathrm{H}$, Eiskjaer $\mathrm{H}$, Botker HE. Is an additional post-myocardial infarction beta-blocker trial required in the era of early revascularization? Eur Heart J. 2004;25:96-7.

10. Freemantle N, Cleland J, Young P, Mason J, Harrison J. beta Blockade after myocardial infarction: systematic review and meta regression analysis. BMJ. 1999:318:1730-7.
11. Bangalore S, Makani H, Radford M, Thakur K, Toklu B, Katz SD, et al. Clinical outcomes with beta-blockers for myocardial infarction: a meta-analysis of randomized trials. Am J Med. 2014;127:939-53.

12. Watanabe $H$, Ozasa N, Morimoto T, Shiomi H, Bingyuan B, Suwa $S$, et al. Long-term use of carvedilol in patients with ST-segment elevation myocardial infarction treated with primary percutaneous coronary intervention. PLoS One. 2018;13:e0199347.

13. Dahl Aarvik M, Sandven I, Dondo TB, Gale CP, Ruddox V, Munkhaugen J, et al. Effect of oral beta-blocker treatment on mortality in contemporary post-myocardial infarction patients: a systematic review and meta-analysis. Eur Heart J Cardiovasc Pharmacother. 2019;5:12-20.

14. Li J, Chen Z, Gao X, Zhang H, Xiong W, Ju J, et al. Meta-analysis comparing metoprolol and carvedilol on mortality benefits in patients with acute myocardial infarction. Am J Cardiol. 2017;120:1479-86.

15. Misumida N, Harjai K, Kernis S, Kanei Y. Does oral beta-blocker therapy improve long-term survival in ST-segment elevation myocardial infarction with preserved systolic function? A meta-analysis. J Cardiovasc Pharmacol Ther. 2016;21:280-5.

16. Huang BT, Huang FY, Zuo ZL, Liao YB, Heng Y, Wang PJ, et al. Meta-analysis of relation between oral beta-blocker therapy and outcomes in patients with acute myocardial infarction who underwent percutaneous coronary intervention. Am J Cardiol. 2015;115:1529-38.

17. Dondo TB, Hall M, West RM, Jernberg T, Lindahl B, Bueno $H$, et al. beta-Blockers and mortality after acute myocardial infarction in patients without heart failure or ventricular dysfunction. J Am Coll Cardiol. 2017; 69:2710-20.

18. Ibanez B, James S, Agewall S, Antunes MJ, Bucciarelli-Ducci C, Bueno H, et al. 2017 ESC Guidelines for the management of acute myocardial infarction in patients presenting with ST-segment elevation: The Task Force for the management of acute myocardial infarction in patients presenting with ST-segment elevation of the European Society of Cardiology (ESC). Eur Heart J. 2018;39:119-77.

19. Amsterdam EA, Wenger NK, Brindis RG, Casey DE Jr, Ganiats TG, Holmes DR Jr, et al. 2014 AHA/ACC guideline for the management of patients with non-ST-elevation acute coronary syndromes: executive summary: a report of the American College of Cardiology/American Heart Association Task Force on Practice Guidelines. Circulation. 2014;130:2354-94.

20. Roffi M, Patrono C, Collet JP, Mueller C, Valgimigli M, Andreotti F, et al. 2015 ESC Guidelines for the management of acute coronary syndromes in patients presenting without persistent ST-segment elevation: Task Force for the Management of Acute Coronary Syndromes in Patients Presenting without Persistent ST-Segment Elevation of the European Society of Cardiology (ESC). Eur Heart J. 2016;37:267-315.

21. The National Institute for Health and Care Excellence. Myocardial infarction: cardiac rehabilitation and prevention of further cardiovascular disease. Available from: https://www.nice.org.uk/guidance/cg172/chapter/1Recommendations\#drug-therapy-2. Accessed 10 May 2019.

22. Gislason GH, Rasmussen JN, Abildstrom SZ, Gadsboll N, Buch P, Friberg J, et al. Long-term compliance with beta-blockers, angiotensin-converting enzyme inhibitors, and statins after acute myocardial infarction. Eur Heart J. 2006;27:1153-8.

23. Korhonen MJ, Robinson JG, Annis IE, Hickson RP, Bell JS, Hartikainen J, et al. Adherence tradeoff to multiple preventive therapies and all-cause mortality after acute myocardial infarction. J Am Coll Cardiol. 2017;70:1543-54.

24. Ko DT, Hebert PR, Coffey CS, Sedrakyan A, Curtis JP, Krumholz HM. Betablocker therapy and symptoms of depression, fatigue, and sexual dysfunction. JAMA. 2002;288:351-7.

25. The National Institute for Health and Care Excellence. Surveillance report 2017 Myocardial infarction: cardiac rehabilitation and prevention of further cardiovascular disease (2013) NICE guideline CG172. Available from: https:/mww.nice.org.uk/ guidance/cg172/resources/surveillance-report-2017-myocardial-infarction-cardiacrehabilitation-and-prevention-of-further-cardiovascular-disease-2013-nice-guidelinecg172-4479686173/chapter/Surveillance-decision?tab=evidence\#reason-for-thedecision. Accessed 10 May 2019.

26. Ibanez B, Raposeiras-Roubin S, Garcia-Ruiz JM. The Swing of beta-Blockers: time for a system reboot. J Am Coll Cardiol. 2017;69:2721-4.

27. Thygesen K, Alpert JS, Jaffe AS, Simoons ML, Chaitman BR, White HD, et al. Third universal definition of myocardial infarction. J Am Coll Cardiol. 2012; 60:1581-98.

28. Chen ZM, Pan HC, Chen YP, Peto R, Collins R, Jiang LX, et al. Early intravenous then oral metoprolol in 45,852 patients with acute myocardial infarction: randomised placebo-controlled trial. Lancet. 2005;366:1622-32. 
29. Hicks KA, Mahaffey KW, Mehran R, Nissen SE, Wiviott SD, Dunn B, et al. 2017 Cardiovascular and stroke endpoint definitions for clinical trials. J Am Coll Cardiol. 2018;71:1021-34.

30. Ko DT, Hebert PR, Krumholz HM. Review: Beta-blockers increase fatigue and sexual dysfunction but not depression after myocardial infarction. ACP J Club. 2003;138:30 author reply.

31. Huffman JC, Celano CM, Beach SR, Motiwala SR, Januzzi JL. Depression and cardiac disease: epidemiology, mechanisms, and diagnosis. Cardiovasc Psychiatry Neurol. 2013;2013:695925.

32. Hayek SS, Ko YA, Awad M, Del Mar Soto A, Ahmed H, Patel K, et al. Depression and chest pain in patients with coronary artery disease. Int J Cardiol. 2017;230:420-6.

33. Montalescot G, Sechtem U, Achenbach S, Andreotti F, Arden C, Budaj A, et al. 2013 ESC guidelines on the management of stable coronary artery disease: the Task Force on the management of stable coronary artery disease of the European Society of Cardiology. Eur Heart J. 2013;34:2949-3003.

34. EuroQol Group. EuroQol--a new facility for the measurement of healthrelated quality of life. Health Policy. 1990;16:199-208.

35. Zigmond AS, Snaith RP. The hospital anxiety and depression scale. Acta Psychiatr Scand. 1983;67:361-70.

36. Rosen RC, Cappelleri JC, Gendrano N 3rd. The International Index of Erectile Function (IIEF): a state-of-the-science review. Int J Impot Res. 2002;14:226-44.

37. Isidori AM, Pozza C, Esposito K, Giugliano D, Morano S, Vignozzi L, et al. Development and validation of a 6 -item version of the female sexual function index (FSFI) as a diagnostic tool for female sexual dysfunction. J Sex Med. 2010;7:1139-46.

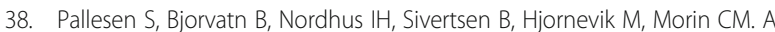
new scale for measuring insomnia: the Bergen Insomnia Scale. Percept Mot Skills. 2008;107:691-706.

39. Spertus JA, Winder JA, Dewhurst TA, Deyo RA, Prodzinski J, McDonell M, et al. Development and evaluation of the Seattle Angina Questionnaire: a new functional status measure for coronary artery disease. J Am Coll Cardiol. 1995;25:333-41.

40. Lithell HO. Insulin resistance and diabetes in the context of treatment of hypertension. Blood Press Suppl. 1998;3:28-31.

41. Vardeny $\mathrm{O}$, Uno H, Braunwald E, Rouleau JL, Gersh B, Maggioni AP, et al. Opposing effects of beta blockers and angiotensin-converting enzyme inhibitors on development of new-onset diabetes mellitus in patients with stable coronary artery disease. Am J Cardiol. 2011;107:1705-9.

42. Lindholm LH, Ibsen H, Borch-Johnsen K, Olsen MH, Wachtell K, Dahlof B, et al. Risk of new-onset diabetes in the Losartan Intervention For Endpoint reduction in hypertension study. J Hypertens. 2002;20:1879-86.

43. Gupta AK, Dahlof B, Dobson J, Sever PS, Wedel H, Poulter NR. Determinants of new-onset diabetes among 19,257 hypertensive patients randomized in the Anglo-Scandinavian Cardiac Outcomes Trial--Blood Pressure Lowering Arm and the relative influence of antihypertensive medication. Diabetes Care. 2008;31:982-8.

44. Munkhaugen J, Ruddox V, Halvorsen S, Dammen T, Fagerland MW, Hernaes $\mathrm{KH}$, et al. BEtablocker Treatment After acute Myocardial Infarction in revascularized patients without reduced left ventricular ejection fraction (BETAMI): Rationale and design of a prospective, randomized, open, blinded end point study. Am Heart J. 2019;208:37-46.

45. Hansson L, Hedner T, Dahlof B. Prospective randomized open blinded endpoint (PROBE) study. A novel design for intervention trials. Prospective randomized open blinded end-point. Blood Press. 1992;1:113-9.

46. Dargie HJ. Effect of carvedilol on outcome after myocardial infarction in patients with left-ventricular dysfunction: the CAPRICORN randomised trial. Lancet. 2001;357:1385-90.

47. Ponikowski P, Voors AA, Anker SD, Bueno H, Cleland JGF, Coats AJS, et al. 2016 ESC Guidelines for the diagnosis and treatment of acute and chronic heart failure: The Task Force for the diagnosis and treatment of acute and chronic heart failure of the European Society of Cardiology (ESC)Developed with the special contribution of the Heart Failure Association (HFA) of the ESC. Eur Heart J. 2016;37:2129-200.

48. Cleland JGF, Bunting KV, Flather MD, Altman DG, Holmes J, Coats AJS, et al. Beta-blockers for heart failure with reduced, mid-range, and preserved ejection fraction: an individual patient-level analysis of double-blind randomized trials. Eur Heart J. 2018;39:26-35.

49. Hong J, Barry AR. Long-term beta-blocker therapy after myocardial infarction in the reperfusion era: a systematic review. Pharmacotherapy. 2018;38:546-54.
50. Goldberger JJ, Bonow RO, Cuffe M, Dyer A, Rosenberg Y, O'Rourke R, et al beta-Blocker use following myocardial infarction: low prevalence of evidence-based dosing. Am Heart J. 2010;160:435-42.e1.

51. Goldberger JJ, Bonow RO, Cuffe M, Liu L, Rosenberg Y, Shah PK, et al. Effect of beta-blocker dose on survival after acute myocardial infarction. J Am Coll Cardiol. 2015;66:1431-41.

52. Allen JE, Knight S, McCubrey RO, Bair T, Muhlestein JB, Goldberger JJ, et al. beta-blocker dosage and outcomes after acute coronary syndrome. Am Heart J. 2017;184:26-36.

53. Charlesworth CJ, Smit E, Lee DS, Alramadhan F, Odden MC. Polypharmacy among adults aged 65 years and older in the United States: 1988-2010. J Gerontol A Biol Sci Med Sci. 2015;70:989-95.

54. Nieuwlaat R, Wilczynski N, Navarro T, Hobson N, Jeffery R, Keepanasseril A, et al. Interventions for enhancing medication adherence. Cochrane Database Syst Rev. 2014:CD000011. https://doi.org/10.1002/14651858. CD000011.pub4.

55. Bueno H, Armstrong PW, Buxton MJ, Danchin N, Lubsen J, Roland E, et al. The future of clinical trials in secondary prevention after acute coronary syndromes. Eur Heart J. 2011;32:1583-9.

\section{Publisher's Note}

Springer Nature remains neutral with regard to jurisdictional claims in published maps and institutional affiliations.

\section{Ready to submit your research? Choose BMC and benefit from:}

- fast, convenient online submission

- thorough peer review by experienced researchers in your field

- rapid publication on acceptance

- support for research data, including large and complex data types

- gold Open Access which fosters wider collaboration and increased citations

- maximum visibility for your research: over $100 \mathrm{M}$ website views per year

At BMC, research is always in progress.

Learn more biomedcentral.com/submissions 